\title{
Evaluation of primary intestinal lymphangiectasia by capsule endoscopy
}

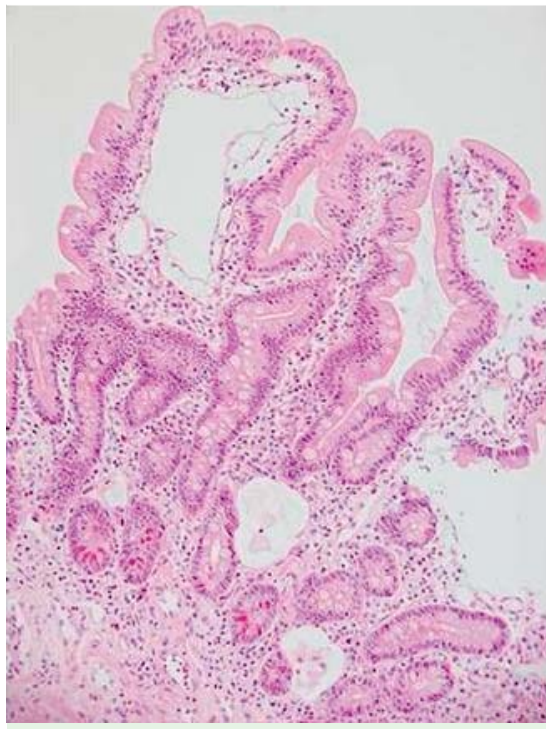

Fig. 1 The intestinal mucosa in a 51-year-old woman with leg and abdominal swelling, and shortness of breath. Endothelial-lined spaces are seen both in the superficial stroma of the villi and in the deeper lamina propria (with the light proteinaceous material inside) (hematoxylin and eosin, magnification $\times 200$ ).

Primary intestinal lymphangiectasia is a rare disease of the intestinal lymphatics, presenting with protein-losing enteropathy, hypoproteinemia, bilateral lower limb edema, and ascites [1-4]. Here we report capsule endoscopic findings in a patient with primary intestinal lymphangiectasia.

A 51-year-old woman was admitted due to swelling of her legs and abdomen, and shortness of breath for nearly 3 years. She did not have diarrhea or weight loss. Her medical history revealed no trauma or abdominal surgery. On physical examination, the breath sounds in the lower lung fields were diminished; there was abdominal swelling and dullness on percussion, and pitting lower-limb edema. Laboratory findings were generally normal except for hypoalbuminemia $(2.42 \mathrm{~g} / \mathrm{dL})$, hypoproteinemia $(4.7 \mathrm{~g} / \mathrm{dL})$, and a low absolute lymphocyte count $\left(850 \mathrm{~mm}^{3}\right)$. Her serum angiotensin-converting enzyme (ACE) level was normal and collagen markers were negative, but serum levels of IgA (78.7 mg/dL; normal $82-453)$ and IgG (555 mg/dL; normal 751 - 1560) were
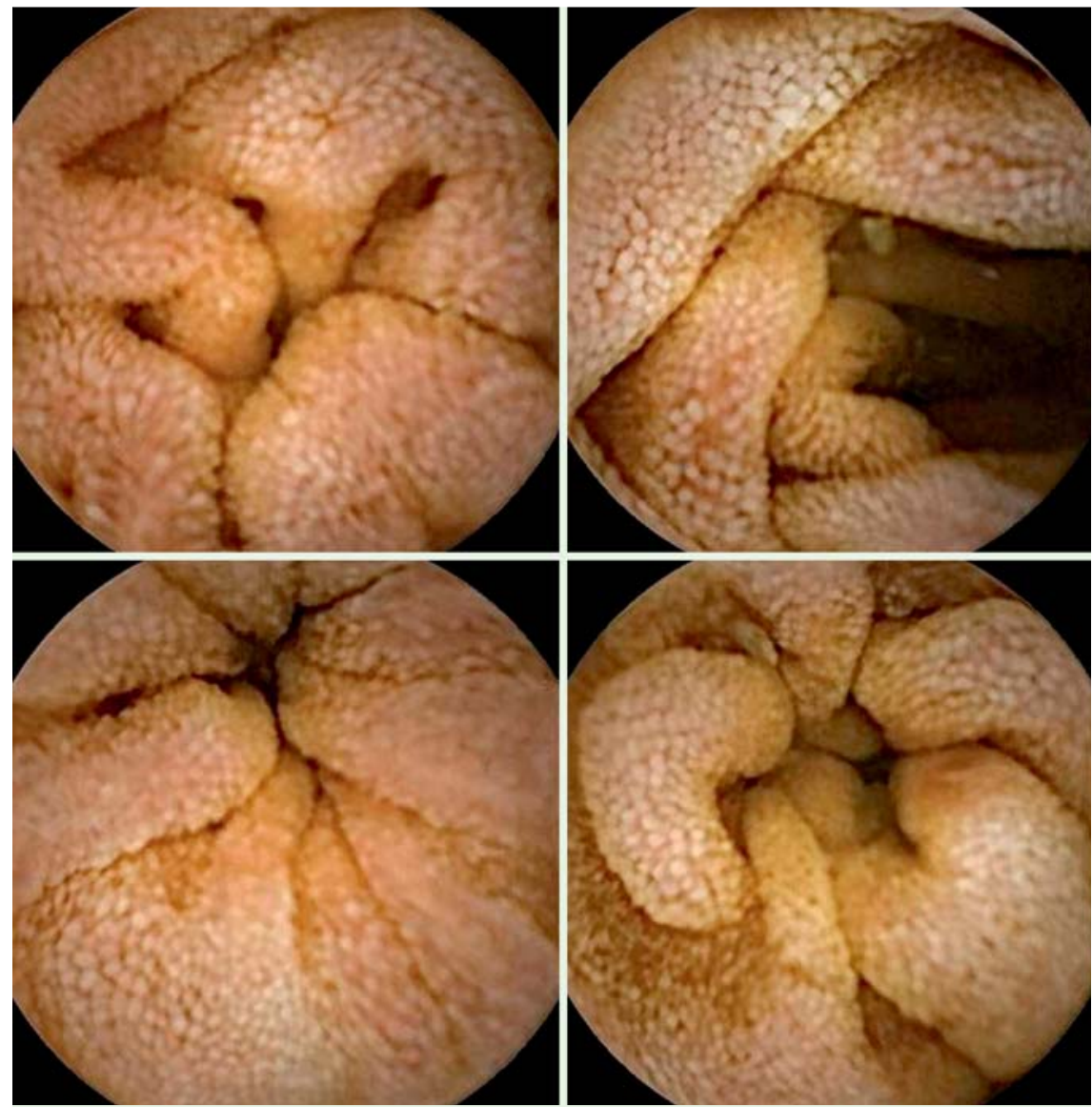

Fig. 2 Capsule endoscopic view showing the diffusely edematous intestinal mucosa covered with enlarged whitish villi.

low. On abdomen ultrasound imaging, only ascites was demonstrated. The examination of ascitic fluid was consistent with chylous ascites: high triglycerides (1700 mg/dL; normal 0-200), low albumin $(0.3 \mathrm{~g} / \mathrm{dL}$; normal 3.5-5.2), low total protein (3.1 g/dL; normal 6.4-8.3), high adenosine deaminase $(47 \mathrm{U} / \mathrm{L}$; normal 0 40 ), and 40 leukocytes $/ \mathrm{mm}^{3}$. Polymerase chain reaction (PCR) analysis on ascitic fluid was negative for tuberculosis. However, endoscopy revealed pinhead-sized, white lesions in the second part of the duodenum. Colonoscopic findings were normal. Histopathologic examination of the duodenal specimens showed dilated lacteals, indicative of intestinal lymphangiectasia ( Fig. 1). Lymphoscintigraphy demonstrated abnormally dilated intestinal lymphatic channels, concordant with intestinal lymphangiectasia, but the exact position of the lesion within the intestine could not be determined. Cardiac echo and magnetic resonance imaging (MRI) did not show any pathology. Capsule endoscopy showed diffuse edematous mucosa in the small intestine, covered by swollen, whitish villi ( Fig. 2). The proximal intestinal mucosa was slightly patchy and atrophic ( Fig.3). In light of all these findings, the patient was diagnosed as having primary intestinal lymphangiectasia. Subssequently, a low-fat diet including medium-chain triglycerides was instituted along with counseling at follow-up.

Endoscopy_UCTN_Code_CCL_1AC_2AB

\section{Competing interests: None}



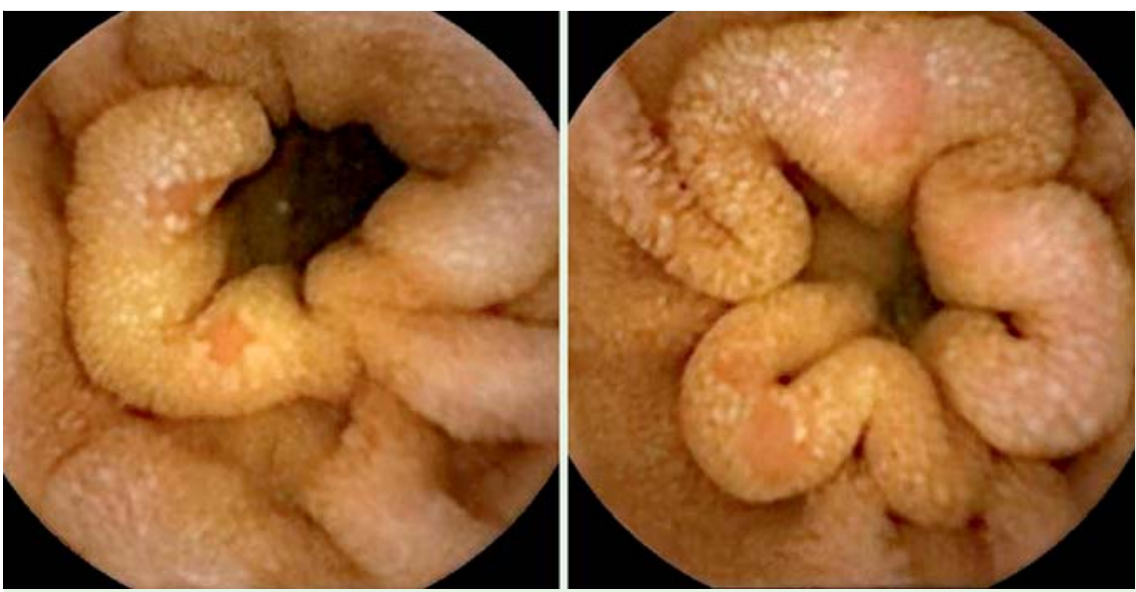

Fig. 3 Capsule endoscopic view showing patchy atrophic mucosa in the proximal small intestine.

\section{O. Ersoy' ${ }^{1}$ E. Akin², A. Demirezer², E. Yilmaz' ${ }^{2}$, T. Solakoglu², C. Irkkan ${ }^{3}$, O. T. Yurekli², S. Buyukasik ${ }^{2}$}

${ }^{1}$ Yildirim Beyazit University, Faculty of Medicine, Department of Gastroenterology, Ankara, Turkey

${ }^{2}$ Ankara Ataturk Education and Research Hospital, Department of Gastroenterology, Ankara, Turkey

\section{${ }^{3}$ Ankara Ataturk Education and Research Hospital, Department of Pathology, Ankara, Turkey}

\section{References}

1 Oh TG, Chung JW, Kim HM et al. Primary intestinal lymphangiectasia diagnosed by capsule endoscopy and double balloon enteroscopy. World J Gastrointest Endosc 2011; 3: $235-240$
2 Fang $Y H$, Zhang $B L, W u$ JG et al. A primary intestinal lymphangiectasia patient diagnosed by capsule endoscopy and confirmed at surgery: a case report. World J Gastroenterol 2007; 13: 2263-2265

3 Wen J, Tang $Q$ Wu J et al. Primary intestinal lymphangiectasia: four case reports and a review of the literature. Dig Dis Sci 2010; 55: $3466-3472$

4 Chamouard P, Nehme-Schuster H, Simler JM et al. Videocapsule endoscopy is useful for the diagnosis of intestinal lymphangiectasia. Dig Liver Dis 2006; 38: 699-703

\section{Bibliography}

DOI http://dx.doi.org/

10.1055/s-0032-1325976

Endoscopy 2013; 45: E61-E62

(c) Georg Thieme Verlag KG

Stuttgart · New York

ISSN 0013-726X

\section{Corresponding author}

\section{O. Ersoy}

Yildirim Beyazit University

Faculty of Medicine,

Department of Gastroenterology

Ankara

Turkey

oersoy@yahoo.com.tr 